\section{Liquor-Zellzählung, mechanisiert}

T. O. Kleine

Institut für Laboratoriumsmedizin und Pathobiochemie, Molekulare Diagnostik Standort Marburg Referenzlabor für Liquordiagnostik, UKGM Universitätsklinikum Gießen und Marburg, Marburg, Deutschland

Englischer Begriff mechanized counting and differentiation of cerebrospinal fluid (CSF) cells

Definition Mechanisierte Zählung und Differenzierung von nativen CSF-Zellen in Hämatologie-Analyzern mittels Streuung am Laserstrahl oder elektrischer Impedanzmessung und chemischer Zellpräparation oder Fluoreszenz-Durchflusszytometrie von Kern-gefärbten CSF-Zellen mit erhöhter Sensitivität in offenen Systemen durch Vermehrung des Probenvolumens. Fluorescence-activated cell sorting (FACS) zu gleichzeitiger Färbung, Analyse und Sortierung von lebenden Leukozyten.

Physikalisch-chemisches Prinzip \ Liquor-Durchflusszytometrie (FACS).

Untersuchungsmaterial Präanalytik: durchsichtige, farblose Polypropylen-Röhrchen steril mit Verschluss.
Probenstabilität: lichtgeschützt bei $4{ }^{\circ} \mathrm{C}<1-2$ Stunden gelagert.

Entnahmebedingungen: $>0,5 \mathrm{~mL}$ frischer Ventrikel-, Subokzipital-(SOP-), Lumbal-Liquor oder (subdurale) Zystenflüssigkeit.

Praktikabilität - Automatisierung - Kosten Schnellere praktikablere Zellzählung mit größerem Probenvolumen $(\geq 100 \mu \mathrm{L})$ als mit zeitaufwendiger Kammerzählung $(10-20 \mu \mathrm{L})$ bei vergleichbar hohen $\mathrm{VK}$ bei niedrigen und hohen Zellzahlen (30-90 \% bzw. $<10 \%$ ); hohe Anschaffungs- und Unterhaltungskosten von HämatologieAnalyzern.

Bewertung - Methodenhierarchie (allg.) Referenzwerte für Leukozyten und Erythrozyten in CSF > Liquor-Zellzählung, mikroskopisch; Leukozytenzählung geeignet im > Liquor-Notfall-Programm, Erythrozytenzählung und Leukozytendifferenzierung in geschlossenen Hämatologie-Analyzern für zellarme CSF-Proben zu unempfindlich.

\section{Literatur}

Kleine TO (1991) Mechanisierte Zählung und Differenzierung von Liquorzellen. Lab Med 15:51-59 